\title{
REVISIONES
}

\section{Aproximaciones al vínculo aparato escolar/trabajo asalariado. Contribuciones de las teorías de la reproducción a las pedagogías críticas}

\author{
School system/wage labor link approaches. Contributions \\ of reproduction theories to critical pedagogy \\ Aproximação ao vínculo sistema escolar/trabalho assalariado. \\ Contribuições das teorias da reprodução à Pedagogia Crítica \\ Paula Ojeda ${ }^{1}$, Jorge Cabaluz ${ }^{2}$ \\ ${ }^{1}$ Pedagogías Críticas y Problemáticas Socio-educativas. \\ Universidad de Buenos Aires, UBA. 8-5773855. pauojedahist@hotmail.com \\ ${ }^{2}$ Pedagogías Críticas y Problemáticas Socio-educativas. Universidad de Buenos Aires, \\ UBA. 3188715. fabiancabaluz@gmail.com
}

\begin{abstract}
RESUMEN
Alejándonos de aquellas lecturas que reifican y naturalizan el vínculo educación/trabajo, proponemos hacer una revisión de aquellos análisis que retoman el carácter complejo, dinámico, interrelacionado y dialéctico de estos dos espacios fundamentales de la actividad humana. Consideramos entonces necesario releer los planteamientos de las teorías reproductivistas, por ser un punto de partida fundamental a la hora de analizar críticamente este vínculo, y particularmente porque lograron instalar perspectivas de análisis relevantes, empapadas de poder y politicidad. En base al diálogo con los textos más significativos de las teorías de la reproducción: "La instrucción en la América capitalista"; "La escuela capitalista en Francia" y "La reproducción", presentamos y problematizamos tres núcleos problemáticos: a) El sistema escolar como reflejo de las relaciones de producción capitalista, b) Las clasificaciones y jerarquías en la dinámica aparato escolar/trabajo asalariado, y c) El problema de la ideología en la relación aparato escolar/trabajo capitalista.
\end{abstract}

Palabras Clave: teorías de la reproducción, escuela capitalista, trabajo asalariado, pedagogías críticas.

\begin{abstract}
Getting away of those readings that reify and naturalize on a sour way the education/work link, we propose to make a review of the those analysis that retake the complex, dynamic, interrelated and dialectical character of this two fundamental spaces of human activity. Then we consider necessary, reread the reproductivist theories statements, for being a fundamental start point when it comes time to give a critical analysis this link and particularly, because they managed to install relevant, soaked of power and politicization analysis perspectives. Based on the dialog with the most significative texts about the reproduction theories; "The education in the capitalist Latin América"; "The capitalist school in France" and "The reproduction", we present and problematize three problematic cores: a) The school system as a reflex of the capitalist production relations, b) The classifications and hierarchy over the school system/wage labor dynamic, and c) The ideological problem on the school system/ capitalist work relation.
\end{abstract}

Key words: theories of the reproduction, capitalist school, work employee, critical pedagogies.

\section{RESUMO}

Distanciando-nos das leituras que materializam e naturalizam o vínculo educação/trabalho, fizemos uma revisão das análises que retomam o caráter complexo, dinâmico, correlacionado e dialético destes espaços fundamentais da atividade humana. Por isso, consideramos necessária a releitura das propostas das teorias reprodutivistas, por estas se constituírem o ponto de partida fundamental ao se analisar criticamente este vínculo, e particularmente, porque instalaram perspectivas de análises relevantes, cheias de poder e política. Baseados no diálogo com os textos mais significativos das teorias de reprodução, A instrução na América capitalista, A escola capitalista na 
França e A reprodução, apresentamos três núcleos problemáticos: a) O sistema escolar como reflexo das relações de produção capitalista; b) As classificações e hierarquias na dinâmica escola/trabalho assalariado e c) O problema da ideologia na relação escola/trabalho capitalista.

Palavras chave: teorias da reprodução, escola capitalista, trabalho assalariado, pedagogias críticas.

\section{POSICIONES TEÓRICO-POLÍTICAS SOBRE LA RELACIÓN EDUCACIÓN/TRABAJO}

En el presente trabajo, proponemos reflexionar acerca del complejo vínculo entre educación y trabajo. Desde una perspectiva amplia, global e interrelacionada abordaremos estos dos espacios fundamentales de la actividad humana, fijando nuestra mirada en la relación entre el sistema escolar y el trabajo asalariado. Dicho análisis lo realizaremos a partir de los planteamientos de las pedagogías críticas.

De manera general, la temática educación/trabajo ha sido abordada distintamente y con importantes matices. Algunos autores han realizado lecturas no conflictivas y con un fuerte carácter funcionalista, destacando la importancia de la educación para el crecimiento económico, subrayando lo determinante de las credenciales educativas en las jerarquías ocupacionales, y su relevancia para la obtención de empleo. Otros, desde una posición más crítica y marcada por las lecturas marxistas y estructuralistas, han analizado el vínculo atendiendo más lo que oculta la dinámica educación/trabajo, y el lugar que ocupa en el modo de reproducción social (Pérez, 1993; Gallart, 1984).

Inicialmente, consideramos la Educación y el Trabajo, como dos aspectos de lo social que se relacionan dialécticamente, que son determinantes y a la vez determinados por la totalidad de relaciones que se dan en una particular formación social. Acordamos que el trabajo -como forma originaria de la praxis social- es el "fundamento de la reproducción del hombre en la sociedad" (Antunes, 2005: 134). Así, al reconocer la centralidad del trabajo en la constitución del ser social, resulta factible agregar que todas las formas de praxis social, por más complejas y avanzadas que sean, jamás pueden desvincularse del proceso del trabajo.

Del mismo modo si entendemos la educación como internalización, proceso en el cual el individuo adopta como propias las metas de reproducción del sistema, podemos decir que lo educativo y lo pedagógico trascienden el espacio escolar y el propio sistema institucional, extendiéndose y manifestándose en el conjunto de la sociedad, en toda la vida social y política. Así, toda relación social es inherentemente pedagógica, por tanto lo pedagógico no puede disociarse del conjunto de la estructura social, inserto en la complejidad de los problemas económicos, políticos y culturales (Mészáros, 2008; Gramsci, 1971). A partir de estos axiomas, resulta entonces impensable disociar lo educativo, lo pedagógico y/o lo escolar del proceso del trabajo.

Recuperando también el concepto de totalidad y sobre-determinación del análisis marxista, nos aproximamos a lo problemático de este vínculo, comprendiendo ambos espacios como partes integradas de un mismo sistema global de producción/reproducción, co-constitutivos entre sí y relacionados de manera dialéctica, conflictiva, dinámica e histórica. Lo social está sobredeterminado, existe un vínculo orgánico entre los elementos que lo constituyen, cuyas partes están en permanente tensión y relación (Althusser, 2004; Williams, 1988; Laclau y Mouffe, 2006). 
Precisamos engarzar nuestra lectura sobre la relación sistema escolar/trabajo asalariado en el marco de la modernidad, entendiendo que el surgimiento de los actuales sistemas educativos se delineó en la sociedad moderna, proceso caracterizado por la consolidación del modo de producción capitalista y la formación del Estado-nación como parte constitutiva de éste. Sostenemos entonces que la invención de los sistemas nacionales de educación van a responder a un dispositivo de regulación social, cuya función es la configuración del sujeto moderno en el marco de un proceso civilizatorio que persigue moldear las actitudes y el comportamiento en aras del nuevo orden económico (Figari y Dellatorre, 2005; Elías, 1993).

Además, entendemos el aparato escolar o el sistema de enseñanza institucionalizado, como parte de un sistema global de internalización, un espacio importante pero no exclusivo de producción y construcción de consenso social, el cual se encuentra restringido temporal y espacialmente, mientras que la dominación ideológica y el adoctrinamiento del capital es continuo y permanente, extendiéndose de múltiples formas a lo largo de toda la vida de los sujetos (Mészáros, 2008).

El marco social donde las prácticas educativas y laborales tienen lugar es el modo de reproducción social metabólico del capital. Acordamos entonces con las lecturas críticas que conciben la educación institucionalizada -considerando las contradicciones, mediaciones, conflictos, luchas y resistencias- como un agente que provee los conocimientos para la máquina productiva del capital; transmite valores, conductas, actitudes, disposiciones y saberes que legitiman y naturalizan el trabajo asalariado; construye el consenso y la conformidad requeridos para la reproducción de la sociedad productora de mercancías; clasifica en su interior a quienes transitan por él, construyendo jerarquías, segmentando, excluyendo y discriminando; disciplina, adoctrina, domestica y controla los comportamientos, emociones y sentimientos de los sujetos en función de los requerimientos del mundo del trabajo; y además contribuye a la alienación y deshumanización de los sujetos mediante procesos de fragmentación, aislamiento e individualización (Fernández Enguita, 1990; Apple, 1997; Antunes, 2003; Giroux, 2004).

Si bien afirmamos la dinámica sistema escolar/trabajo asalariado bajo la lógica absorbente del capital, creemos que sus funciones y objetivos van más allá de los imperativos del capital, de los ajustes del patrón de acumulación y la nueva organización del trabajo. Sostenemos que lo social se encuentra sobredeterminado, que existe un vínculo orgánico entre todos los elementos que lo constituyen, por tanto, la relación sistema escolar/trabajo asalariado debe ser comprendida en coexistencia con distintos y múltiples mecanismos de producción/reproducción social, como parte de un todo, interrelacionado, integrado, complementario, contrapuesto y antagónico. Sólo de este modo podemos viabilizar y proyectar una idea de la educación y del trabajo como espacios vitales para la sociabilidad y la autorrealización humana, que posibilite recuperar un sentido de la educación y del trabajo integrado y liberador.

En este sentido, los planteamientos de las teorías reproductivistas son un punto de partida fundamental a la hora de analizar críticamente este vínculo. Nuestra propuesta es hacer una revisión de sus planteamientos, en base al diálogo con las lecturas de $L a$ instrucción en la América capitalista de Samuel Bowles y Hebert Gintis; La escuela capitalista en Francia, de Christian Baudelot y Roger Establet y "La reproducción" de Pierre Bourdieu y Jean Claude Passeron, presentando y problematizando tres núcleos problemáticos: a) El sistema escolar como reflejo de las relaciones de producción 
capitalista, b) Las clasificaciones y jerarquías en la dinámica aparato escolar/trabajo asalariado, y c) El problema de la ideología en la relación aparato escolar/trabajo capitalista.

\section{LAS TEORÍAS DE LA REPRODUCCIÓN. MATRIZ CRÍTICA DE LA RELACIÓN EDUCACIÓN/TRABAJO}

Las teorías de la reproducción se caracterizaron por realizar una crítica radical al papel de la educación en la reproducción del orden social existente, buscaron esclarecer la relación entre la escuela y el orden social capitalista, preguntándose cómo ésta contribuye a reproducir las relaciones sociales de producción necesarias para la existencia y perpetuación del sistema social. Mostrándose críticos a las concepciones de la escuela como una institución neutra y ajena a los intereses de grupos particulares, instalaron la problemática del poder y de las clases sociales para abordar los temas de la cultura, desestabilizando las teorías liberales que concebían la escuela como espacio fundamental para la igualación de las diferencias sociales, políticas, económicas y culturales, que persistían en la sociedad (Tedesco, 1983; Giroux, 2004).

Abordando la relación educación y sistema productivo, educación y sistema de clases, concluyeron que la educación participa activamente en la reproducción y conservación de las relaciones sociales capitalistas: distribuyendo, legitimando y recompensando los conocimientos propios de la cultura dominante; sancionando las características culturales de otros grupos sociales; contribuyendo a la formación de una fuerza de trabajo diferenciada; entregando a los individuos los conocimientos y la capacitación necesaria para ocupar un determinado lugar en la división social del trabajo; inculcando la ideología burguesa, etc. (Giroux, 2004).

Aunque sus planteamientos son coincidentes sobre el papel de la educación en el sistema productivo, se advierten matices en la forma en cómo es planteada esta relación, interpretación sustentada en base a la compresión marxista de la dinámica entre la estructura/superestructura, economía/cultura, sistema productivo/sistema escolar. La escuela efectivamente cumple una función en la reproducción del capital, pero no podemos olvidar la coexistencia de otros factores -políticos, culturales e ideológicos- que introducen mediaciones importantes o generan desajustes entre las demandas educativas y las necesidades del mercado.

\subsection{NÚCLEO PROBLEMÁTICO.}

\section{El sistema escolar como reflejo de las relaciones de producción capitalistas}

Para Bowles y Gintis, el funcionamiento del sistema escolar sólo puede comprenderse mediante un análisis sustantivo de las instituciones económicas; únicamente describiendo la estructura de la vida económica y la dinámica particular de las relaciones sociales de producción, es posible comprender la dinámica del cambio educativo. Plantean mirar las escuelas a la luz de las relaciones sociales y económicas, puesto que los aspectos primordiales de la organización educativa son una réplica de las relaciones de dominación y subordinación de la esfera productiva. 
Las relaciones de dominación y subordinación capitalistas logran conservarse y perpetuarse principalmente por la forma en que está organizado el proceso de producción, cuyas particularidades deben reproducirse en otros entornos sociales -como la escuelapara que todas las relaciones sociales se desplieguen acordes con los principios de la vida económica.

Las organizaciones sociales del trabajo se caracterizan por ser jerárquicas y burocráticas, espacios donde la fragmentación, la rutinización y la falta total de control obrero sobre el proceso de trabajo son fundamentales para las ganancias burguesas y para la perpetuación de privilegios en una sociedad clasista. La desigualdad es parte central de la división jerárquica del trabajo, ésta se materializa en puestos de diferente autoridad, prestigio y responsabilidad -cuya asignación aparenta ser objetiva y eficiente y por consecuente, justa e igualitaria- asociado a un ingreso diferenciado que contribuye a legitimar la estructura de autoridad y reducir la solidaridad obrera, fortaleciendo la fragmentación y la competencia entre los trabajadores.

Así también, la organización vertical y el principio de autoridad en la escuela es una réplica de la división jerárquica del trabajo. En ella se producen las capacidades cognoscitivas y técnicas requeridas para desenvolverse en el mundo laboral, necesarias para contribuir a la rentabilidad de la empresa. Fomenta la idea del mérito como productor del éxito económico, responsabilizando al individuo/estudiante por su logro o fracaso en el sistema escolar y sus implicancias en la vida adulta, preparándolo a aceptar el lugar que se le ha asignado en la división social del trabajo. La escuela, además, clasifica, reproduce y recompensa determinadas características personales, convenientes con la distribución de puestos de trabajo, premiando la conciencia estratificada mediante la competencia institucionalizada entre los estudiantes, colaborando a la fragmentación de la clase subordinada y a la reproducción del trabajo fragmentado y alienado (Bowles y Gintis, 1985). En resumen, el sistema educativo aporta en la reproducción de las relaciones sociales de producción, gestando una fuerza de trabajo fragmentada, enajenada y disciplinada, porque existe una correspondencia entre las relaciones sociales de la instrucción escolar con las del trabajo.

Aunque se reconoce que el sistema escolar tiene una dinámica propia, insisten en la determinación económica sobre las habilidades, hábitos, valores, normas y conocimientos que son adquiridos en el sistema escolar, sin enfatizar adecuadamente en el carácter dialéctico de la relación. Por tanto, los patrones cambiantes de la reforma educativa son determinados por los cambios en la organización social de la producción y los conflictos que en ella tienen lugar:

Los lineamientos básicos del sistema educativo estadounidense y los conflictos que periódicamente cimbran sus bases, y vuelven a canalizar su desarrollo, pueden entenderse más claramente a través de un análisis de las fuerzas contradictorias que operan en el sistema. La lucha entre la clase obrera y el capital en la economía tiene su contrapartida en el conflicto educativo (Bowles y Gintis, 1985: 136).

En síntesis, mediante un amplio despliegue de fuentes estadísticas, descriptivas e históricas, Bowles y Gintis sostienen que la educación reproduce la diferenciación de la estructura social capitalista, porque es ésta la que determina el funcionamiento del sistema educativo. Los procesos de enseñanza/aprendizaje en las escuelas cumplen con preparar a los estudiantes/trabajadores para que puedan integrarse sin conflictos en la estructura jerárquica que define el modelo de relaciones laborales, porque son congruentes con las 
necesidades de la economía capitalista. Definitivamente, son las transformaciones del capital y su dinámica el motor de las reformas educativas; el sistema escolar va sufriendo modificaciones a medida que se producen los cambios en los procesos de producción o por la conflictividad laboral, propia de esos espacios.

Por su parte, Bourdieu y Passeron problematizan el concepto de la educación como reflejo. Sus esfuerzos apuntan a comprender la dinámica interna y la estructura singular del sistema de enseñanza francés. Analizan la escuela en relación a la estructura de clases, para plantear la existencia de una afinidad estructural y funcional entre los sistemas educativos tradicionales y el sistema de valores de la clase privilegiada. La escuela valora y legitima la cultura de la clase dominante, la inculca y reproduce mediante una acción pedagógica, que es violencia simbólica, puesto que mediante un conjunto de coacciones busca inculcar e imponer una cultura determinada como legítima.

Desde este lugar, podemos inferir de los autores una dinámica particular de la relación estructura/superestructura. La reproducción de las clases no se produce únicamente en la estructura económica, ya que el campo cultural -donde la escuela como principal instancia de legitimación del arbitrario cultural contribuye a la reproducción de la estructura de la distribución del capital cultural entre las clases- también cumple funciones de reproducción de las relaciones de clase existentes. Para sostener su propuesta, trabajan con el concepto de autonomía relativa del sistema escolar.

Bourdieu y Passeron plantean que el sistema económico impone exigencias al sistema educativo, pero son críticos a las lecturas que reducen las funciones del sistema de enseñanza a las meras necesidades del mercado; el proceso de reproducción es mucho más complejo, puesto que el sistema de enseñanza está atravesado por múltiples demandas tanto externas como internas. Claramente el sistema de enseñanza absorbe las demandas de selección social en función de una economía capitalista, pero este proceso no es simple ni lineal, no está exento de problemas.

El sistema de enseñanza retraduce y reinterpreta las demandas de reproducción y de legitimación de la estructura de las relaciones de clases, pero guardando coherencia con sus estructuras internas. Para los autores no es posible ignorar la especificidad y autonomía relativa del sistema de enseñanza, porque "Un sistema de enseñanza debe su estructura singular tanto a las exigencias transhistóricas que definen su función propia de inculcación de una arbitrariedad cultural como al estado del sistema de funciones que especifica históricamente las condiciones en las cuales se realiza esta función" (Bourdieu y Passeron, 1998; p. 241). El sistema educativo no es un reflejo del sistema social, se debe a sí mismo, de allí que cuando realiza sus funciones externas, lo haga de una forma particular y específica. La metáfora del reflejo ensombrece las funciones diferenciales que realizan los distintos subsistemas -como el sistema de enseñanza- en su relación y su dependencia respecto a la estructura de las relaciones de clase. Por esto instalan el concepto de mediatización para comprender las interrelaciones entre los subsistemas.

\subsection{NÚCLEO PROBLEMÁTICO}

\section{Clasificaciones y jerarquías en la dinámica aparato escolar/trabajo asalariado}

La producción de clasificaciones en el aparato escolar debe ser comprendida en relación a las diferentes clasificaciones que están en juego en el espacio social. Si el espacio que 
estructura la organización de las relaciones sociales es la sociedad capitalista, las clasificaciones y jerarquías que construye el aparato escolar se entremezclan y se constituyen a partir de las jerarquías sociales que valoran dicho orden (Rozenblatt, 1999).

Para los sociólogos Christian Baudelot y Roger Establet, la escuela capitalista -como parte de los aparatos ideológicos del Estado- reproduce mediante complejos mecanismos ideológicos y materiales las relaciones sociales de producción, el sistema de clases y la dominación burguesa, por consiguiente asegura también las clasificaciones y jerarquías que producen las relaciones sociales capitalistas.

Sostienen que el aparato escolar aparenta ser unitario y unificador -continuo y complementario en sus diferentes niveles-, pero lo que realmente hace es dividir, clasificar, seleccionar y segregar a los individuos que transitan por él, estableciendo diferencias según el origen de clase. El aparato escolar divide a la población escolarizada en dos grupos desiguales y en dos tipos de escolaridad: "una escolaridad larga, reservada a una minoría, y una escolaridad corta, premio de la mayoría" (Baudelot y Establet, 1997: 34), instituyendo en su interior dos redes de escolarización: la red primaria-profesional y la red secundaria-superior.

Cada red de escolarización forma diferenciadamente a los estudiantes, porque la escolarización en la sociedad capitalista desempeña un papel directo en la condición de clase de los sujetos. La división material en la escuela y producida por el aparato escolar contribuye a constituir las dos clases fundamentales para la reproducción capitalista. Ambas redes son herméticas, heterogéneas y opuestas entre sí, llegando a sostener como hipótesis central que "las clases socialmente antagónicas pasan por dos redes de escolarización opuestas que ocupan los dos polos del proceso de escolarización" (Baudelot y Establet, 1997: 68).

Las diferencias entre ambas redes se materializan en prácticas escolares concretas y cotidianas, impartiendo arbitrariamente las "calificaciones" y/o "competencias" escolares requeridas por el mercado del trabajo. La red primaria-profesional se caracteriza por emplear prácticas monótonas e insistentes, repite los conocimientos adquiridos en la escuela primaria y pone énfasis en lo concreto y en lo manual. Forma hábitos y juicios, desplegando una pedagogía no directiva con métodos activos que devuelven la seguridad al estudiante, la confianza y el afecto, y requiere de un bajo costo para su funcionamiento. Es una formación fuertemente orientada al trabajo asalariado y la fábrica. Mientras que la red secundaria-superior se caracteriza por realizar prácticas de continuidad y gradualidad progresiva, funcionan en base a la emulación y la selección individual, los contenidos se complejizan gradualmente y se encuentran orientados a la educación superior, por lo que otorgan relevancia al saber enciclopédico y al conocimiento libresco (Baudelot y Establet, 1997).

El hermetismo y el carácter antagónico de ambas redes aseguran prácticamente la imposibilidad de que los estudiantes se traspasen de una red a otra. En términos muy esquemáticos, los autores aseguran que quienes ingresan a la red primaria-profesional son expulsados de ella o ingresan directamente a la producción -cuando el mercado laboral lo permite- asumiendo generalmente puestos subalternos; así como quienes ingresan a la red secundaria-superior terminan accediendo a la educación superior, ocupando puestos directivos, y sólo en contadas excepciones terminan en la red primaria-profesional. Cabe aclarar que las dos redes de escolarización no asignan directamente un puesto de trabajo individual en la sociedad, ya que su asignación en los mismos depende también 
del mercado del trabajo. Baudelot y Establet aseguran que las dos redes se combinan con los imperativos del mercado laboral, para ubicar así a los sujetos en los respectivos lugares de la división social y técnica del trabajo.

La selección de los estudiantes se basa en el rendimiento escolar individual, lo cual se asocia en el capitalismo a la productividad del trabajador, es decir, a la relación producción/tiempo. Los malos resultados, el bajo rendimiento y el retraso escolar deben comprenderse en relación con el origen social y la división del trabajo. Reafirmando esto, los autores señalan: "Existe por consiguiente una red de escolarización que produce y reproduce a aquellos a los que se denomina, con un término eminentemente ambiguo, como los trabajadores manuales. [Y] existe, en el extremo opuesto, una red de escolarización que produce y reproduce a los trabajadores intelectuales" (Baudelot y Establet, 1997: 97).

Con respecto al tema, y sin dar cuenta de las dos redes de escolarización descritas por Baudelot y Establet, los estadounidenses Bowles y Gintis reconocen la función clasificatoria del aparato escolar, y sostienen que la correspondencia entre la instrucción escolar y las relaciones sociales de producción se materializa también en las jerarquías que organizan el sistema escolar en diferentes niveles de educación y centros de enseñanza.

El aparato escolar está organizado en su interior de forma equivalente a la división jerárquica del trabajo, así entonces, los diferentes niveles de educación se corresponden con los diferentes niveles de la estructura ocupacional. En los niveles más bajos de la jerarquía ocupacional se aprecia el respeto a las reglas; en los niveles medios, la dependencia y la capacidad de operar sin supervisión directa: y en los niveles altos se fomenta la interiorización de las normas de la empresa. De igual manera, están estructuradas las diferentes escuelas para encauzar determinadas normas comportamentales en los estudiantes en correspondencia con las jerarquías de producción; incluso, al interior de una misma escuela se dispone de un orden diferenciado. "Así, en el bachillerato, las ramas vocacionales y generales destacan el respeto por las reglas y la supervisión estrecha, mientras que la rama universitaria tiende a una atmósfera más abierta que destaca la interiorización de los normas" (Bowles y Gintis, 1985: 177).

El recorrido por los diferentes centros y niveles educativos está determinado no sólo por el origen de clase, también la desigualdad de los recursos financieros que las familias destinan en la educación de los hijos encauzan el tipo de escuela y las relaciones sociales que en ella se afirman.

El sistema de relaciones de clase, raza y sexo que ha sido conformado y vuelto a conformar constantemente por la evolución de la estructura de la producción así como el desarrollo desigual de la economía capitalista ha quedado reflejado en la estructura segmentada, estructurada jerárquicamente, racista, sexista, nativista de la educación estadounidense (Bowles y Gintis, 1985: 303).

Finalmente, Pierre Bourdieu y Jean Claude Passeron sostienen que el sistema escolar y la estructura ideológica que lo sustenta no es neutra ni objetiva en relación a las clases sociales, infiriendo que las clasificaciones y jerarquías que se constituyen en el espacio escolar no obedecen exclusivamente a una lógica interna del sistema de enseñanza, sino que éstas están íntimamente relacionadas con la lógica de las jerarquías sociales en una sociedad de clases. Es decir, el sistema de enseñanza retraduce en términos educativos las demandas de selección social, produciendo y reproduciendo las desigualdades. 
A pesar de que las clases sociales se relacionan distintamente con el sistema de enseñanza y que su origen de clase condiciona las disposiciones con respecto a la escuela, ésta también suma y contribuye a reproducir y legitimar la estratificación social. Mediante un complejo mecanismo de selección, eliminación y ocultación de la eliminación de la selección -sancionando las diferentes caracterizaciones culturales y sociales de los estudiantes, valorando el capital lingüístico de las clases privilegiadas, encauzando y atrayendo diferencialmente a las distintas clases sociales en los tipos de estudios y tipos de centros de enseñanza, asegurando desigualdades para acceder a la enseñanza superior-, transforma la desigualdades sociales en desigualdades escolares.

El sistema de enseñanza contribuye a legitimar las diferencias de clase y a perpetuar la estructura de privilegios, mediante una movilidad controlada de un número limitado de individuos, aparentado movilidad social y garantizando de esta forma la estabilidad y la conservación social.

\subsection{NÚCLEO PROBLEMÁTICO}

\section{El problema de la ideología en la relación aparato escolar/trabajo capitalista}

Baudelot y Establet plantean que la escuela capitalista -entendida como aparato ideológico del Estado- contribuye a la reproducción de las relaciones sociales de producción capitalista mediante la imposición e inculcación de la ideología burguesa. Para los autores, la inculcación ideológica es distribuida diferencialmente en una y otra red de escolarización, y se manifiesta en la red primaria-profesional mediante la imposición de subproductos empobrecidos y vulgarizados de la cultura burguesa. En ella se simplifican las ideas burguesas, promulgando la defensa de sus intereses e instituciones, haciendo prácticos, tangibles y concretos, todos aquellos procesos que son complejos, abstractos y contradictorios. Mientras que en la red secundaria-superior, se inculca una serie de aprendizajes (contenidos, habilidades, valores, disposiciones, etc.) que permiten a los estudiantes convertirse en intérpretes y actores efectivos de la ideología dominante.

Conforme plantean, el capitalismo no puede promover una misma formación ideológico-cultural a explotadores y explotados, "la burguesía inculca en y a través del aparato escolar una misma ideología -la ideología burguesa- tanto a los futuros burgueses como a los futuros proletarios. Pero esta misma ideología es inculcada bajo formas diferentes en una y otra red" (Baudelot y Establet, 1997: 151). Por tanto, la dominación ideológica de la clase dominante no implica uniformidad, sino más bien una serie de diferenciaciones que demarcan la condición de clase.

La inculcación ideológica diferenciada que se realiza en las dos redes de escolarización impone a los futuros trabajadores un cuerpo compacto de ideas simples, y en los burgueses una serie de aprendizajes que permiten fortalecer, (re) crear y promover su propia ideología. A modo de ejemplo, los autores explican cómo en los libros de texto empleados para la alfabetización de adultos en Francia se construye una imagen armónica y fetichizada del trabajo, que borra los conflictos, oculta las relaciones de explotación, presenta el salario como recompensa, glorifica la disciplina y la obediencia, y reivindica el esfuerzo personal como el principal motor de la promoción social.

$\mathrm{Al}$ adscribir la conceptualización althusseriana del aparato escolar como aparato ideológico del Estado, los autores reconocen que la escuela es un aparato de lucha al servicio de 
la burguesía, un instrumento de dominación y una herramienta prioritariamente ideológica. Ahora bien, la ideología materializada en prácticas sociales, y en este caso en prácticas escolares, evidencia de diferentes maneras la conflictividad social entre el capital y el trabajo. En el seno del aparato escolar, visualizan históricamente diferentes expresiones ideológicas de la lucha de clases, las que en el capitalismo logran imponer la ideología burguesa, rechazando, coartando y subalternizando la ideología de los trabajadores.

Baudelot y Establet, reconocen el aparato escolar como un espacio de contradicciones y luchas ideológicas, en él se manifiestan diferentes formas de resistencia, las cuales son rechazadas y reprimidas, pero jamás eliminadas. Las resistencias presentes en los aparatos ideológicos del Estado (escuelas, sindicatos, familias, iglesias, partidos políticos, prensa, radio, televisión, literatura, artes y deporte), rechazan de modo no organizado ni teorizado la dominación ideológica de la burguesía. Estas resistencias o "formas instintivas de conciencia de clase" se manifiestan de forma pacífica o violenta, prioritariamente contra los dispositivos de disciplinamiento y contra la multiplicidad de formas de inculcación ideológica (Baudelot y Establet, 1997).

En relación al aparato escolar y la inculcación de la ideología dominante, Bourdieu y Passeron enfatizan en la variedad de funciones ideológicas que cumple el sistema de enseñanza y nos alertan sobre las lecturas reduccionistas, que vinculan únicamente ideología con adoctrinamiento. Destacan la centralidad del sistema de enseñanza en la inculcación ideológica, porque al ser la principal instancia legítima de legitimación del arbitrario cultural y tener el control y monopolio de la violencia simbólica, logran -mediante su aparente autonomía relativa- ocultar la verdadera naturaleza de las diferencias escolares.

Al sostener que el aparato escolar y la estructura ideológica que lo fundamenta están estrechamente relacionados con la estructura de las relaciones de clases, subrayan que la función ideológica principal del sistema de enseñanza es ocultar y enmascarar la verdad objetiva de su funcionamiento, justificando ideológicamente el orden social que contribuye a reproducir.

Se detienen en el carácter encubridor de la ideología al insistir que el aparato escolar enmascara la relación entre el origen social y los resultados escolares, y que oculta su contribución a la reproducción de la distribución del capital cultural entre las clases. Asimismo, su carácter legitimador se manifiesta cuando sostiene y legitima, -con la ideología escolar del mérito, de la igualdad de oportunidades y de las credenciales educativas- la reproducción circular de las jerarquías sociales y las jerarquías escolares.

En un papel legitimador de las jerarquías sociales, la escuela confirma y refuerza un particular habitus de clase -constituido por fuera de la escuela-, al exigir uniformemente a todos los que pasan por el sistema de enseñanza una relación con el lenguaje y la cultura que se adquiere sólo por familiarización y que es propio de las clases dominantes. Mediante la imposición e inculcación de la ideología burguesa y la cultura dominante, logra interiorizar los principios del arbitrario cultural, proceso que hace posible la reproducción.

Por su parte, Bowles y Gintis subrayan que el funcionamiento del sistema económico requiere para su estabilidad y viabilidad disponer de mecanismos explícitos que permitan conservar y sostener los patrones de dominación y subordinación existentes. Uno de los dispositivos fundamentales ha sido el recurso ideológico, porque contribuye a legitimar la estructura de clases y facilitar el buen funcionamiento de las instituciones económicas.

Según los autores, la fachada ideológica ha servido para justificar los patrones de privilegio, legitimando un orden social, logrando su estabilidad y permanencia mediante 
"el fomento entre individuos de una conciencia generalizada que evita la formación de nexos sociales y la compresión crítica mediante las cuales es posible la transformación de la realidad" (Bowles y Gintis, 1985: 139).

La reproducción de la conciencia, necesaria y fundamental para la reproducción de las clases sociales, no se transmite exclusivamente en los aparatos culturales, ésta se produce y reproduce en la experiencia cotidiana. De allí que los autores sostengan que todas los espacios y relaciones sociales -donde la experiencia cotidiana tiene lugar- están organizados concientemente a fin de facilitar la reproducción de la conciencia en función de un orden social capitalista (Bowles y Gintis, 1985). El sistema educativo -en conjunto con una serie de instituciones sociales estrechamente relacionadas con la formación de la personalidad y la conciencia- es estructurado mediante un simple principio de correspondencia para reproducir la conciencia de los estudiantes/trabajadores hacia una mayor armonía del sistema económico.

La educación, en su papel de legitimar la estructura de clases, la desigualdad económica y las relaciones de producción, fomenta formas de conciencia congruentes con la reproducción de clase. Impulsa la ideología de la igualdad de oportunidades educativas e interioriza la ideología tecnocrática-meritocrática, que ha servido para justificar la organización burocrática, las líneas jerárquicas de autoridad, la fragmentación de las tareas y las desigualdades remunerativas, características de la organización del trabajo en la sociedad capitalista, ayudando a considerarla como natural y legítima.

El sistema educativo facilita la aceptación de las relaciones sociales de producción, al propiciar un entorno competitivo en la escuela, al afirmar que el éxito escolar es producto de la capacidad y la perseverancia, la motivación y el sacrificio, y que el fracaso en el aula es resultado de la falta de atributos personales, reconciliando a los estudiantes con sus respectivas posiciones en la sociedad, justificando la estratificación social y las jerarquías laborales. En otras palabras, la escuela acostumbra a los jóvenes a una serie de relaciones sociales similares a las del trabajo, encauzando el desarrollo de las necesidades personales hacia los requerimientos del sistema: “(...) el sistema educativo da forma a los conceptos de sí mismo, a las aspiraciones y a las identificaciones de clase social de los individuos, y a los requisitos de la división social del trabajo" (Bowles y Gintis, 1985: 173).

\section{REFLEXIONES FINALES. LA RELACIÓN EDUCACIÓN/TRABAJO MÁS ALLÁ DE LAS TEORÍAS DE LA REPRODUCCIÓN}

a) Los análisis de los teóricos de la reproducción sobre el aparato escolar fueron un intento por superar las interpretaciones del "marxismo vulgar" sobre la metáfora del edificio y del reflejo, que establecía una relación mecánica y causal de la base económica sobre la superestructura. Sus abordajes, anclados en las conceptualizaciones marxistas, complejizaron diferenciadamente la idea de la escuela y de lo cultural como epifenómeno, superando los análisis que consideraban estas esferas de lo social irrelevantes o no determinantes en el proceso histórico.

$\mathrm{Al}$ analizar la escuela como espacio privilegiado y central en la reproducción de las relaciones sociales capitalistas, advirtieron que las instituciones escolares no son espacios aislados, neutros y ajenos a lo social, y sostuvieron la tesis de la existencia de vínculos estrechos entre el Estado, los sistemas de enseñanza y la economía. 
El concepto de autonomía relativa que utilizaron los autores para referirse al aparato escolar, revela sus intentos por complejizar la idea del epifenómeno. El sistema escolar como parte de lo social no es indiferente a las determinaciones externas, sin embargo, éstas son recibidas de una manera particular que hace que la correspondencia entre la estructura educativa y la vida económica no sea del todo perfecta y armoniosa (Bowles y Gintis, 1985), puesto que ésta retraduce y reinterpreta las demandas de reproducción y de legitimación de la estructura de las relaciones de clases, guardando coherencia con sus estructuras internas (Bourdieu y Passeron, 1998).

Si bien las investigaciones avanzaron en develar las conexiones entre la economía, el Estado y el sistema de enseñanza, vínculos que hacían de la dominación un proceso estable y permanente, no lograron desarrollar adecuadamente una teoría que incorpore las contradicciones que operan en esos espacios, es decir, cómo las distintas determinaciones externas e internas, múltiples y variadas de lo social, actúan restringiendo, limitando y atenuando las determinaciones de la esfera económica.

Reafirmamos que lo social está sobredeterminado y que un análisis sobre las instituciones formales como la escuela no puede quedar restringido a las contradicciones de la esfera económica, como tampoco al reconocimiento de la profunda influencia que tienen éstas sobre el proceso social. La escuela no sólo reproduce la dinámica de clase y las relaciones sociales de producción, también produce/reproduce otras relaciones de dominación basadas en la raza, la etnia, el género, entre otras, y que requieren ser esclarecidas por las pedagogías críticas para avanzar hacia un análisis de lo educativo que incorpore una perspectiva más dinámica, dialéctica y relacional.

Por tanto, creemos que las propuestas de los teóricos de la reproducción, fueron iniciales e impulsaron un adecuado reconocimiento de las conexiones indisolubles existentes entre la producción material y las actividades e instituciones políticas y culturales, pero cayeron en conceptualizaciones como la idea del reflejo, que nos dificultan avanzar hacia una mayor compresión del vínculo sistema de enseñanza/trabajo asalariado, puesto que imposibilita entenderla como un proceso activo y mediatizado.

Finalmente, no debemos caer -como hicieron los reproductivistas- en modelos de dominación completos, uniformes y libres de contradicción. El concepto gramsciano de hegemonía, retomado por Raymond Williams, es pertinente en este sentido, puesto que entiende la hegemonía como dominación, pero nunca de un modo total. Las resistencias y las oposiciones se encuentran siempre presentes, tanto en la escuela como el lugar de trabajo, porque son espacios en disputa, marcados por las relaciones de fuerza existentes en lo social, y que hacen de la hegemonía siempre un proceso activo y dinámico, que debe ser permanentemente recreada, modificada y transformada (Williams, 1988).

b) Con respecto a los procesos de clasificación generados en y por el aparato escolar y los espacios laborales, los teóricos de la reproducción se centraron en denunciar, desnaturalizar y visibilizar las funciones de división, selección y segregación social que caracterizan a estos espacios, tensionando particularmente el discurso igualitario y de promoción social impulsado por la escuela. Aunque concordamos en que los procesos de selección escolar, son correspondientes con las necesidades del aparato productivo, y que por tanto sus estratificaciones responden a las necesidades de control y explotación de una economía capitalista, discrepamos de la lectura reduccionista de las clasificaciones en función de dos clases fundamentales antagónicas. La congruencia absoluta 
entre la selección escolar y jerarquía ocupacional no logra dar cuenta de la complejidad social y de sus múltiples diferenciaciones. Las variables sociales y políticas -no sólo las económicas- son centrales también en la determinación tanto de la organización de la estructura escolar como de las jerárquicas del mercado de trabajo, en otros términos, afirmamos que el aparato escolar se organiza en tensión con la división jerárquica del trabajo, el género, la raza, el grupo etario, etc.

Resulta fructífero el abordaje de la institución escolar como legitimadora de las jerarquías sociales, ocultando mediante credenciales educativas determinadas posiciones en la estructura ocupacional y social. Ahora bien, la expansión cuantitativa en cuanto al acceso al sistema educativo ha incrementado los grados de escolarización de la fuerza de trabajo, restando relevancia a los grados y títulos escolares, e incrementando las lógicas de selección y de jerarquías del mercado de trabajo. La función diferenciadora del mercado de trabajo supone que la diferenciación social está perdiendo uno de sus soportes más significativos de legitimación: la educación. En este marco, las pedagogías críticas no sólo deben cuestionar y tensionar-simbólica y materialmente- los procesos de cristalización de jerarquías impulsados en el sistema educativo y laboral, sino también disputar los criterios y las lógicas clasificatorias de la dominación (Tedesco, 1983).

Así también, las pedagogías críticas deben nutrirse de los aportes de la sociología crítica del trabajo. Sus abordajes sobre el problema de las clasificaciones y su implicación en los conceptos de calificación y competencia, nos permiten refinar las relaciones análogas entre las técnicas empresariales para identificar y evaluar las competencias, y las técnicas desplegadas en la escuela para definir los conocimientos y evaluar su adquisición. Además, los estudios sobre el actual patrón de dominación, la doctrina de la flexibilidad y el paradigma de la calidad total, han demostrado cómo se han transformado los procesos clasificatorios, mediante la generación de nuevas lógicas de profesionalización, expresando su incidencia en la reestructuración de contenidos escolares, re-orientando no solo el sentido de ese conocimiento, sino también estableciendo así nuevas formas de distribución de poder, lo cual modifica las formas y criterios de selección y clasificación establecidos por el patrón fordista y taylorista (Figari, 2003; Rozemblatt, 1999; Tanguy, 2003).

c) Los planteamientos de las teorías de la reproducción sobre el papel de las ideologías en la relación entre el aparato escolar y el trabajo asalariado, si bien son diferentes y enfatizan en diversos aspectos, entregan importantes contribuciones a las pedagogías críticas, ya que nutren el análisis de lo escolar y lo laboral, mediante la desnaturalización y el desvelamiento del carácter político-ideológico presente en las relaciones sociales que los constituyen, permitiendo así visibilizar los intereses de clase (y en menor medida de género y raza) inmersos en ellos. Además, al incorporar en sus análisis la dimensión ideológica como un recurso que contribuye a legitimar la estructura de clases, la división socio-técnica del trabajo, la distribución desigual del capital cultural, la desigualdad económica y las relaciones de producción capitalistas, han permitido politizar e introducir la conflictividad del poder presente en estas relevantes esferas de lo social.

Otro aspecto relevante son sus reflexiones sobre las formas materiales que asume la ideología en el espacio escolar y laboral. Según sus planteamientos, la ideología se materializa en prácticas sociales, lo cual posibilita analizar el problema político del poder y la dominación -en la escuela, la fábrica, la universidad, la empresa, etc.- relacionado 
con las formas de organización y funcionamiento del espacio, el tiempo, las rutinas y los rituales. Así, los teóricos de la reproducción entrelazaron con gran claridad la relación existente entre el trabajo industrial y los rituales escolares, la distribución témporo-espacial del aparato escolar, sus jerarquías internas, la organización de su infraestructura, los usos del timbre, el uniforme, etc. (Willis, 1988).

Sus abordajes de la ideología como inculcación, no sólo de conocimientos y saberes cargados de politicidad y de intereses de clase, sino también entendidos como actitudes y habilidades y disposiciones apropiadas para el lugar de trabajo, carecieron de la complejidad adecuada, al acentuar el papel ideológico solo en la conformación de las relaciones de dominación, y no en cómo éste actúa en las relaciones de lucha y resistencia. A partir de aquí, emerge un conjunto de críticas a las teorías reproductivistas, por el carácter unidimensional que otorgan a la dominación, reduciendo lo escolar a un espacio reproductor de una fuerza de trabajo dócil y disciplinada, donde la conflictividad, las contradicciones y las luchas son minimizadas y reducidas frente al poder totalizador de la dominación. En este sentido, la ideología no fue analizada en términos dialécticos, sino como una forma de opresión incorregible, perpetua y estática (Giroux, 2004; Apple, 1997; Tedesco, 1983).

Las teorías de la reproducción restaron relevancia a la subjetividad, la conciencia y la experiencia, cayendo en posiciones que reducían o negaban la participación del sujeto en la transformación de los procesos históricos. La noción de inculcación ideológica minimiza la subjetividad del estudiante y del trabajador, y no reconoce los procesos de mediación mediante los cuales se produce y reproduce la dominación social. El sujeto social es considerado un mero sostén de las estructuras sociales, y así planteado, ¿qué posibilidades de construcción contra-hegemónica pueden impulsarse desde los espacios escolares y laborales? Desde una perspectiva política, el "pesimismo paralizante" inmerso en las teorías de la reproducción ha sido duramente criticado.

Del mismo modo, la relación directa establecida entre ideología y clase social también ha sido cuestionada. En este sentido, resulta erróneo referirse a la ideología burguesa y la ideología proletaria, ya que las ideologías que benefician a las clases dominantes pueden ser legitimadas y consensuadas por las clases subalternas, y viceversa. La ideología es un terreno en disputa que a través del trabajo de deseos y miedos, o mediante construcciones simbólicas puede movilizar a los diferentes grupos sociales hacia posiciones completamente insospechadas (Apple, 1997).

Resulta entonces pertinente analizar las resistencias escolares y laborales, y sus expresiones contra-culturales, sin ensalzarlas como germen de la ideología proletaria o la conciencia de clase. La ideología dominante puede encontrarse confirmada cuando se naturaliza las divisiones sociales, sexuales y raciales, o cuando no se problematizan las jerarquías, la competitividad, el individualismo, el trabajo manual, etc. Las resistencias y las expresiones contra-culturales poseen potencialidades en términos de creatividad, construcción colectiva, rechazo a la obediencia, al conformismo, a la autoridad, a el control del tiempo, a las normas institucionales y a las jerarquías, pero no son prácticas sociales conscientes, no prefiguran necesariamente elementos de la sociedad por venir y carecen de organización política, lo cual limita sus posibilidades transformadoras (Willis, 1988).

Finalmente, nos interesa reafirmar que las teorías de la reproducción son una piedra angular para analizar las relaciones entre educación/trabajo y sistema escolar/trabajo asalariado, ya que si bien han sido enormemente cuestionadas por las teorías críticas en educación, lograron instalar perspectivas de análisis relevantes y empapadas de poder y politicidad. 


\section{REFERENCIAS BIBLIOGRÁFICAS}

Althusser, L. (2004). La revolución teórica de Marx. Buenos Aires: Siglo XXI Editores.

Anderson, P. (2005). Consideraciones sobre el marxismo occidental. Buenos Aires: Siglo XXI.

Antunes, R. (2005). Los sentidos del trabajo. Ensayo sobre la afirmación y la negación del trabajo. Buenos Aires: Ediciones Herramienta.

Antunes, R. (2003). ¿Adiós al trabajo? Ensayo sobre la metamorfosis y el rol central del mundo del trabajo. Buenos Aires: Ediciones Herramienta.

Apple, M. (1997). Teoría crítica y educación. Buenos Aires: Miño y Dávila.

Baudelot, C. y Establet, R. (1997). La escuela capitalista. Buenos Aires: Siglo XXI Editores.

Bourdieu, P. y Passeron, J. (1998). La reproducción. Elementos para una teoría del sistema de enseñanza. México D.F.: Distribuciones Fontamara.

Bowles, S. y Gintis, H. (1985). La instrucción escolar en la América capitalista. Madrid: Siglo XXI Editores.

Elías, N. (1993). El Proceso de la civilización. Investigaciones sociogenéticas y psicogenéticas. Argentina: Fondo de Cultura Económica.

Figari, C. (2003). Los jóvenes profesionales y la formación del mando en el nuevo orden empresario: agencia simbólica e itinerarios de profesionalización emergentes. En 6to Congreso Nacional de Estudios del Trabajo. Buenos Aires: Asociación de Especialistas en Estudios del Trabajo.

Figari, C. (2005). El orden capitalista y el trabajo asalariado: disciplinamientos y resistencias. En C. Figari y C. Delatorre, La cuestión educacional en la modernidad: discursos legitimadores de la dominación cultural (4-19). Argentina. Universidad Nacional de Luján.

Fernández Enguita, M. (1990). La cara oculta de la escuela. España, Siglo XXI Editores.

Frigotto, G. (1981). La productividad de la escuela improductiva. Buenos Aires: Miño y Dávila.

Gallart, M. (1986). Educación y Trabajo: Un estado del arte de la investigación en América Latina. Otawa: International Development Research Centre Manuscript Reports.

Giroux, H. (2004). Teoría y resistencia en educación. México: Siglo XXI Editores.

Gramsci, A. (1971). El materialismo histórico y la filosofía de Benedetto Croce. Buenos Aires: Ediciones Nueva Visión.

Gramsci, A. (1981). La alternativa pedagógica. Barcelona: Fontamara.

Mészárós, I. (2008). La educación más allá del capital. Argentina: Siglo XXI Ediciones/CLACSO.

Montes Cató, J. (2005). La configuración del poder en los espacios de trabajo, dispositivos disciplinarios y resistencia de los trabajadores. En Sociología del Trabajo. Buenos Aires: Nueva época, Núm. 54.

Pérez Gómez, A. (1993). Las funciones sociales de la escuela: de la reproducción a la reconstrucción crítica del conocimiento y la experiencia. En Gimeno Sacristán, J. y Pérez Gómez, A. Comprender y transformar la enseñanza. (17-33). Madrid: Morata.

Rozemblatt, P. (1999). El cuestionamiento del trabajo. Clasificaciones, jerarquía, poder. Buenos Aires: Piette, Serie Seminarios Intensivos de Investigación.

Tanguy, L. (2003). De la evaluación de los puestos a la de las cualidades de los trabajadores. Definiciones y usos de la noción de competencias. En De La Garza y Neffa (Comps.). El futuro del trabajo-el trabajo del futuro. Buenos Aires: Clacso.

Tedesco, J. (1983). Critica al reproductivismo educativo. Cuadernos Políticos, Número 37. (56-69). México D.F.: Editorial Era.

Torres, C. (1979). Ideología, educación y reproducción social. Revista de la Educación Superior. Asociación Nacional de Universidades e Instituciones de Educación Superior. México. http:// www.anuies.mx/servicios/p_anuies/publicaciones/revsup/res032/txt3.htm

Williams, R. (1988). Marxismo y literatura. Barcelona: Península.

Willis, P. (1988). Aprendiendo a trabajar. Cómo los chicos de la clase obrera consiguen trabajos de la clase obrera. Madrid: Editorial Akal. 
